\title{
Proteomic analysis of the effects of CSF-1 and IL-1 $\alpha$ on dental follicle cells
}

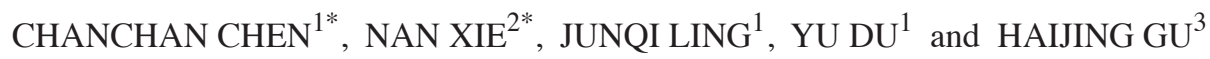 \\ Departments of ${ }^{1}$ Operative Dentistry and Endodontics, ${ }^{2}$ Oral Pathology and ${ }^{3}$ Pediatric Dentistry, \\ Guanghua School of Stomatology, Research Institute of Stomatology, Guangdong Province Key Laboratory of Stomatology, \\ Sun Yat-sen University, Guangzhou, Guangdong 510055, P.R. China
}

Received June 4, 2015; Accepted May 23, 2016

DOI: $10.3892 / \mathrm{mmr} .2016 .5567$

\begin{abstract}
Tooth eruption is a complex physiological process involving both osteogenesis and bone resorption. Signals from the dental follicle (DF) regulate bone remodeling during tooth eruption. Interleukin-1 $\alpha$ (IL-1 $\alpha$ ) may be the initial promoter of tooth eruption, whereas colony-stimulating factor-1 (CSF-1) may attract monocytes into the DF and stimulate osteoclast differentiation. In the present study, differential proteomics was employed to explore protein changes in rat DF cells (DFCs) under the effects of CSF-1 and IL-1 $\alpha$. A total of 47 protein spots were differentially expressed in rat DFCs, and 40 protein spots were identified by MALDI-TOF-MS. The identified proteins were grouped into functional categories including cytoskeletal proteins, metal-binding proteins, proteins involved in secretion and degradation, cell cycle proteins and stress proteins. In IL- $1 \alpha$-induced rat DFCs, 31 proteins were upregulated compared with the control and included heat shock protein $\beta$-1 (HSP25, also known as HSP27/HSP $\beta 1$ ), vimentin, TMEM43, the GTP-binding protein Rab-3D, 6-pyruvoyl tetrahydrobiopterin synthase and actin. In total, 7 proteins were downregulated, including serum albumin, GIPC1, DNA primase large subunit, cullin-5 and cyclin-G1. In $\mathrm{CSF}-1$-induced rat DFCs, 3 proteins were upregulated and 7 proteins were downregulated when compared with the controls. The upregulated proteins included the GTP-binding protein Rab-3D and $\alpha$-actin. The downregulated proteins included cullin-5, serum albumin, PDZ domain-containing protein and cyclin-G1. The differential expression of vimentin, actin, HSP25 and Rab-3D was verified by western blotting and
\end{abstract}

Correspondence to: Dr Junqi Ling, Department of Operative Dentistry and Endodontics, Guanghua School of Stomatology, Research Institute of Stomatology, Guangdong Province Key Laboratory of Stomatology, Sun Yat-sen University, 56 Ling Yuan Xi Road, Guangzhou, Guangdong 510055, P.R. China

E-mail: lingjq@mail.sysu.edu.cn

*Contributed equally

Key words: proteomics, dental follicle cells, IL-1 $\alpha$, CSF-1, tooth eruption reverse transcription-quantitative polymerase chain reaction analyses. The present findings provide an insight into the mechanisms involved in tooth eruption.

\section{Introduction}

Tooth eruption is a complex physiological process whereby teeth migrate to functional spaces from the jaw. For a tooth to erupt, the alveolar bone must be resorbed to create an eruption pathway (1), and a biological process must exist that will result in the tooth moving through this eruption pathway. The dental follicle (DF) is a loose connective tissue that surrounds the enamel organ and dental papilla of the developing tooth germ, prior to eruption (2). One of the biological functions of the DF is the coordination of tooth eruption (3). Before differentiation into osteoclasts, osteoclast precursors are recruited into the DF; a process that is necessary for bone resorption and the initiation of the eruption pathway (4).

Osteoclast recruitment and activation during the various stages of tooth eruption depend on complex signaling mechanisms that have been elucidated in recent decades (5). The regulatory factors expressed in the DF or the satellite reticulum include macrophage colony-stimulating factor-1 (CSF-1) (6), monocyte chemoattractant protein (MCP-1) (7), nuclear factor- $k \mathrm{~B}(\mathrm{NF}-k \mathrm{~B})$, interleukin- $1 \alpha(\mathrm{IL}-1 \alpha)$ and its receptor (IL-1R type I), epithelial growth factor (EGF), osteoprotegerin $(\mathrm{OPG})$, tumor necrosis factor superfamily member 11 (RANKL) and c-fos. These factors interact to form the regulatory system of tooth eruption (8).

CSF-1 and IL-1 $\alpha$ serve important roles in tooth eruption. CSF-1 is a glycoprotein growth factor that specifically stimulates the survival, proliferation and differentiation of cells of the mononuclear phagocytic lineage (9). CSF-1 attracts monocytes into the DF and stimulates osteoclast differentiation. In the process of first mandibular molar eruption in rats, CSF-1 is expressed at its highest level on post-natal days 3 and 10, when the peak of osteoclastogenesis occurs. The increased expression of CSF-1 elevates the level of c-fos and downregulates OPG on the third day (8). Once osteoclasts are recruited to the alveolar crypt bone located around the tooth germ, RANKL/OPG signaling persists during the successive stages of eruptive movement, in order to modulate resorptive activity (5). The occlusal portion of the DF produces CSF-1, 
and CSF-1-mutant rats are toothless (10). Thus, CSF-1 is a major osteoclastogenesis factor during tooth eruption. Another factor that is involved in both osteoclastogenesis and tooth eruption is IL- $1 \alpha$. A previous study observed that IL- $1 \alpha$ is located in the stellate reticulum, and its receptor (IL-1R type I) is present in the adjacent DF (11). Compared with wild-type controls, the time of eruption for the first mandibular molar in IL-1R null mice was delayed by 2 days. Additionally, IL-1 $\alpha$ contributes to the upregulation of CSF-1, MPC-1 and NF- $k \mathrm{~B}$ expression in DF cells (DFCs), which indicates that IL- $1 \alpha$ may be the initial promoter of tooth eruption.

However, the signaling mechanisms that occur in the DF during the process of tooth eruption remain elusive. To date, studies regarding the molecular mechanisms of tooth eruption have focused primarily on the function of single or a number of associated genes or proteins, and only a few have investigated the gene and protein profiles of DFCs after osteogenic differentiation (12-14). In the current study, the effects of CSF-1 and IL-1 $\alpha$ on DFCs were investigated in vitro using differential proteomics techniques.

\section{Materials and methods}

DFC culture and treatments. All animal procedures were approved by Ethics Committee of the Guanghua College of Stomatology at Sun Yat-sen University (Guangzhou, China). DFs were isolated from the first mandibular molars of Sprague-Dawley rats [5-7 days old, supplied by the Laboratory Animal Center of Sun Yat-sen University (Guangzhou, China)], and digested using $0.1 \%$ collagenase type I and $10 \mathrm{U} / \mathrm{ml}$ dispase (Sigma-Aldrich, St. Louis, MO, USA) for $30 \mathrm{~min}$ at $37^{\circ} \mathrm{C}$ to obtain DFCs as described previously (15). To ensure a uniform cell population, the DFCs were cultured for 3-4 passages at $37^{\circ} \mathrm{C}$ and $5 \% \mathrm{CO}_{2}$ in Dulbecco's modified Eagle's medium (DMEM, low glucose; GE Healthcare Life Sciences, Logan, UT, USA) supplemented with $10 \%$ fetal bovine serum (FBS: Gibco; Thermo Fisher Scientific, Inc., Waltham, MA, USA) and $1 \%$ penicillin/streptomycin. DFCs at passages 3-5 were used in all subsequent experiments.

DFCs were grown in T-25 flasks until cells reached $80-90 \%$ confluence. Cells were then cultured for an additional $24 \mathrm{~h}$ in serum-free DMEM prior to experimental treatments. DFCs were treated with rat CSF-1 or IL-1 $\alpha$ (PeproTech China, Jiangsu, China) at a concentration of $50 \mathrm{ng} / \mathrm{ml}$ for $12 \mathrm{~h}$. The DFCs were collected for protein isolation following the designated treatments, and the treatments were repeated three times, each with a different set of DFC cultures.

Hematoxylinandeosin(HE)staining andimmunocytochemistry. The first molar germs of rats were fixed overnight at $4^{\circ} \mathrm{C}$ in $4 \%$ formaldehyde diluted in phosphate-buffered saline (PBS), and were routinely prepared for paraffin embedding. Serial 5-mm sections were prepared, collected on 3-aminopropyltriethoxysilane-coated slices and air-dried. The sections were deparaffinized, rehydrated and stained with $\mathrm{HE}$, and then dehydrated, cleared and mounted.

DFCs at passage 3 were seeded in 48-well plates until they reached $50-60 \%$ confluence. The cells were fixed with $4 \%$ formaldehyde for $15 \mathrm{~min}$ at room temperature, blocked with $1 \%$ bovine serum albumin for $1 \mathrm{~h}$, and incubated overnight at $4^{\circ} \mathrm{C}$ with antibodies against vimentin (catalog no. BM0135; Wuhan Boster Biological Technology, Ltd., Wuhan, China) and keratin (catalog no. BM0031; Wuhan Boster Biological Technology, Ltd.) diluted 1:1,000, or PBS as a negative control. Subsequently, biotinylated-goat anti-mouse IgG (catalog no. BA1001; Wuhan Boster Biological Technology, Ltd.) diluted 1:1,000 was added and samples were incubated at $37^{\circ} \mathrm{C}$ for $30 \mathrm{~min}$, washed 3 times with PBS for $3 \mathrm{~min}$, stained with 3,3'-diaminobenzidine and counterstained with hematoxylin. Cells were imaged using an inverted microscope (Zeiss GmbH, Jena, Germany).

Protein extraction. Following the removal of culture medium from the flasks, cells were washed 3 times with ice-cold Tris-buffered sucrose solution. Cells were carefully scraped from the bottom of the flask and incubated on ice for $10 \mathrm{~min}$ in $100 \mu \mathrm{l}$ of standard lysis buffer containing $7 \mathrm{~mol} / \mathrm{l}$ urea, $2 \mathrm{~mol} / \mathrm{l}$ thiourea, 4\% CHAPS buffer (GE Healthcare Life Sciences, Uppsala, Sweden) and $30 \mathrm{mmol} / 1$ Tris buffer. Cell lysates were sonicated on ice and the nuclear fraction was removed by centrifugation at $20,000 \times \mathrm{g}$ for $30 \mathrm{~min}$ at $4^{\circ} \mathrm{C}$. Protein samples were purified using a Clean-Up kit (GE Healthcare Life Sciences), and protein concentrations were measured with a Quant kit (GE Healthcare Life Sciences) according to the manufacturer's instructions.

CyDye labeling. Protein extracts were labeled with the CyDye Difference Gel Electrophoresis (DIGE) Fluor (Minimal Dye) Labeling kit (GE Healthcare Life Sciences) according to the manufacturer's instructions. The internal standard was prepared by combining equal amounts of the 12 test samples. A total of 6 DIGE gels were used to analyze the control or treatment samples. A total of $50 \mathrm{mg}$ of protein from control or treatment cultures was labeled with $1 \mu \mathrm{l}$ of $\mathrm{Cy} 3$ or $\mathrm{Cy} 5$ working dye solution, and $50 \mathrm{mg}$ the internal standard mixture was labeled with Cy2 (Table I). Samples were then incubated on ice for $30 \mathrm{~min}$ in the dark. Reactions were quenched with the addition of $2 \mu \mathrm{l}$ of $10 \mathrm{mmol} / 1$ lysine for $10 \mathrm{~min}$ on ice in the dark. Cy3 and Cy5-labeled samples and the Cy2-labeled internal standard were then pooled prior to two-dimensional (2D)-DIGE analysis.

2D-DIGE and two-dimensional electrophoresis (2-DE). Protein samples were loaded onto dry strips ( $\mathrm{pH}$ 4.0-7.0, $24 \mathrm{~cm}$; GE Healthcare Life Sciences). Rehydration, isoelectric focusing and equilibration were performed using the methods described previously (16). The DIGE gels were visualized using a Typhoon Variable Mode Imager 9400 (GE Healthcare Life Sciences). A total of 2 preparative gels, each containing $500 \mathrm{mg}$ of unlabeled internal standard mixture proteins extracted from 12 samples (6 control and 6 treatment samples), were also analyzed. Following the 2-DE, 2 preparative gels were stained with Deep Purple (0.5\%: GE Healthcare Life Sciences) and scanned. The emission filters were $488 \mathrm{~nm}$ (Cy2; blue), $532 \mathrm{~nm}$ (Cy3; green), $633 \mathrm{~nm}$ (Cy5; red) and $532 \mathrm{~nm}$ (Deep Purple) with a resolution of $100 \mu \mathrm{m}$.

Image analysis. Protein expression analysis was performed using the differential in-gel analysis (DIA) module and the DeCyder 6.0 software (GE Healthcare Life Sciences, Fairfield, 
CT, USA). A value of 3,000 was set as the initial estimate of the number of protein spots present. The intensities of individual protein spots within the proteomes of the control and treatment samples were compared. These DIA analyses were collated into a single analysis using the DeCyder biological variation analysis module, and the final values for the expression ratio of specific protein spots between control and treatment samples were determined. Student's $t$-test was used to calculate significant differences in the relative abundance of individual protein spot features between control and stimulated samples. Protein spots with mean abundance ratios $>1.5$ or $<-1.5$ were selected and added to a list of proteins of interest.

In-gel digestion and matrix-assisted laser desorption/ionization-time of flight (MALDI-TOF)-mass spectrometry (MS). Spot map images generated from Deep Purple post-stained preparative gels were matched to the analytical 2D-DIGE gels. The picking of selected protein spots from the preparative gels, in-gel digestion, peptide extraction, preparation of the samples for MS and spotting on target slides, were conducted automatically with an Ettan spot handling workstation (GE Healthcare Life Sciences) as described previously (16). Protein identification by peptide mass fingerprinting (PMF) was performed using an Ultraflex III MALDI-TOF-MS spectrometer (GE Healthcare Life Sciences) operating in the reflectron mode. The PMF results were searched by Mascot (Matrix Science Ltd., London, UK). The search parameters were as follows: Database, Swissprot; species of search, rat; database retrieval, combined; maximum missed cleavages, 1 ; enzyme, trypsin; fixed modification, carbamidomethylation (Cys); variable modifications, oxidation (Met); and peptide mass tolerance, $100 \mathrm{ppm}$, MA/MS 0.7 D. Identified proteins were grouped into functional categories according to information from the UniProt database (www.uniprot. org) and DAVID (http://niaid.abcc.ncifcrf.gov/home.jsp), in combination with BLAST (www.ncbi.nlm.nih.gov/BLAST/) alignment results.

Western blot analysis. Control and stimulated DFCs were harvested in Laemmli buffer, sonicated and centrifuged at $12,000 \times \mathrm{g}, 4^{\circ} \mathrm{C}$ for $5 \mathrm{~min}$. Total protein was measured using a Bio-Rad Coomassie Blue protein assay (Bio-Rad Laboratories Inc., Richmond, CA, USA). A total of $20 \mu \mathrm{g}$ protein was diluted in $10 \%$ bromophenol blue, boiled, separated by sodium dodecyl sulfate-polyacrylamide gel electrophoresis and transferred to a nitrocellulose membrane. The membranes were blocked in 5\% low-fat milk at room temperature for $1 \mathrm{~h}$, rinsed, and incubated with goat anti-vimentin (1:200; catalog no. sc-7558; Santa Cruz Biotechnology, Inc., Dallas, TX, USA), sheep anti-actin (1:1,000: catalog no. AF4000; R\&D Systems China Co., Ltd., Shanghai, China), rabbit anti-HSP25 (1:1,000; catalog no. SPA-801; Stressgen; Enzo Life Sciences, Inc., Farmingdale, NY, USA), goat anti-Rab-3D (1:200; catalog no. sc-26559; Santa Cruz Biotechnology, Inc.) or mouse anti-tubulin (1:1,000; catalog no. ab173840; Abcam, Shanghai, China) overnight at $4^{\circ} \mathrm{C}$. Membranes were then incubated with the horseradish peroxidase (HRP)-conjugated secondary antibodies rat anti-goat IgG (catalog no. BA1060; Wuhan Boster Biological Technology, Ltd.), bovine anti-sheep IgG (catalog no. sc-2701; Santa Cruz Biotechnology, Inc.), goat anti-rabbit IgG (catalog no. BA1055; Wuhan Boster Biological Technology, Ltd.), or goat anti-mouse IgG (catalog no. BA1050; Wuhan Boster Biological Technology, Ltd.), at a dilution of 1:1,000. Protein bands were visualized using Immobilon Western Chemiluminescent HRP Substrate (EMD Millipore, Billerica, MA, USA). The expressed bands were detected by ImageQuant ${ }^{\mathrm{TM}}$ LAS 4000 mini (GE Healthcare Life Sciences) and the densitometry was measured using ImageJ software version 2 (National Institutes of Health, Bethesda, MD, USA).

Reverse transcription-quantitative polymerase chain reaction $(R T-q P C R)$. Total RNA was isolated with TRIzol reagent (Invitrogen; Thermo Fisher Scientific, Inc.) following the manufacturer's protocol. mRNA quantification was performed using the ABI 7300 Real-Time PCR System (Applied Biosystems; Thermo Fisher Scientific, Inc.). Complementary DNA (cDNA) was synthesized with a RevertAid First Strand cDNA Synthesis kit (Thermo Fisher Scientific, Inc.) in a final volume of $20 \mu \mathrm{l}$. Reverse transcription was performed at $37^{\circ} \mathrm{C}$ for $1 \mathrm{~h}$ followed by a 10 -min incubation at $70^{\circ} \mathrm{C}$ to inactivate the reverse transcriptase. Subsequently, $5 \mu 1$ reaction mixture was incubated with FastStart Universal SYBR Green Master Mix (Rox: Roche Diagnostics, Basel, Switzerland) in a final volume of $10 \mu \mathrm{l}$. Primers used for RT-qPCR are presented in Table II. All reactions were run using a hot-start pre-incubation step of $10 \mathrm{~min}$ at $95^{\circ} \mathrm{C}$, followed by 40 cycles of $15 \mathrm{sec}$ at $95^{\circ} \mathrm{C}, 60 \mathrm{sec}$ at $60^{\circ} \mathrm{C}$, and a final 5-min step at $60^{\circ} \mathrm{C}$. The amount of RNA was quantified using the comparative quantification cycle $(\mathrm{Cq})$ method according to the manufacturer's protocol. Relative gene expression was calculated using the $2^{-\Delta \Delta \mathrm{Cq}}$ method (17) with glyceraldehyde 3-phosphate dehydrogenase (GAPDH) as an internal control.

Statistical analysis. Experiments were repeated a minimum of three times with three independent cell samples. Data were expressed as the mean \pm standard deviation. Student's $t$-test was used to calculate significant differences between control and stimulated samples. $\mathrm{P}<0.05$ was considered to indicate a statistically significant difference. Statistical analyses were performed using SPSS software (version 13.0; SPSS Inc., Chicago, IL, USA).

\section{Results}

Isolation and visualization of rat DFCs. As shown in Fig. 1A and $\mathrm{B}$, the DF is the outer layer of the tooth germ surrounding the enamel organ and the dental papilla. Primary DFCs were isolated from rat first mandibular molars. After the molars were cultured in vitro for 2-3 days, rat DFCs were observed around the rat DF (Fig. 1C). The majority of the DFCs exhibited a fusiform shape after 2 passages (Fig. 1D). Immunocytochemical staining showed that passage 3 cells were vimentin-positive (Fig. 1E) but negative for keratin 1 (Fig. 1F), which confirmed DFCs originating from the mesenchyme were obtained.

Treatment of rat DFCs with IL-1 $\alpha$ or CSF-1 alters protein expression profiles. 2D-DIGE was used to compare the protein expression profiles between control and treated DFCs (Fig. 2). The data were analyzed using the DeCyder image analysis 
software. A total of 47 protein spots with a $>1.5$-fold upregulation or downregulation were identified in the 6 gels. A total of 37 protein spots were identified in the IL- $1 \alpha$-treated DFC samples, with 31 proteins observed to be upregulated and 6 downregulated, compared with the controls (Table III). A total of 10 protein spots were identified in the CSF-1-treated DFC samples, with 3 proteins found to be upregulated and 7 downregulated compared with the controls (Table III). A partial view of the protein spots from the $2 \mathrm{D}$ gel and $3 \mathrm{D}$ images are presented in Fig. 3.

Identification and functional grouping of protein spots by MALDI-TOF-MS. To identify the 47 protein spots flagged by the image software, preparative gels containing $500 \mathrm{mg}$ of each extract were run and stained with Deep Purple. The protein spots were matched to the CyDye-labeled images by the DeCyder software, excised from the gel and digested with trypsin. Peptide mass maps were obtained from MALDI-TOF PMF analysis, and 40 proteins were identified (Table III). The identified proteins were grouped into functional categories, which included cytoskeletal proteins, metal-binding proteins, proteins involved in secretion and degradation, cell cycle proteins and stress proteins. In IL- $1 \alpha$-induced rat DFCs, cytoskeletal proteins, stress proteins and proteins involved in secretion (such as HSP25), vimentin, transmembrane protein 43 (TMEM43), the GTP-binding protein Rab-3D, 6-pyruvoyl tetrahydrobiopterin synthase (PTPS) and actin. However, proteins associated with protein degradation, metal-binding and the cell cycle including serum albumin, GIPC PDZ domain containing family member 1 (GIPC1), DNA primase large subunit, cullin-5 and cyclin-G1, were observed to be downregulated (Table III). In CSF-1-induced rat DFCs, 3 proteins were found to be upregulated and 7 proteins were downregulated compared with the control group. Upregulated proteins consisted of the GTP-binding protein Rab-3D and $\alpha$-actin. Downregulated proteins included cullin-5, serum albumin, PDZ domain-containing protein and cyclin-G1 (Table III).

Verification of protein analysis by western blotting and $R T-q P C R$. Western blotting and RT-qPCR analyses were performed on 4 proteins of interest (vimentin, actin, HSP25 and Rab-3D) to confirm the results obtained from the DIGE gels. For all transcripts studied, a significant difference between the expression levels in the control and treated groups was observed. The mRNA levels of vimentin $(\mathrm{P}=0.0315)$, actin $(\mathrm{P}=0.0446), \operatorname{HSP} 25(\mathrm{P}=0.0004)$ and Rab-3D $(\mathrm{P}=0.0112)$ were significantly upregulated within the IL- $1 \alpha$ and CSF-1-treated cultures compared with the control cultures. The results for mRNA and protein expression were similar (Fig. 4). The data obtained by western blotting and RT-qPCR analyses supported the DIGE results for the analyzed proteins.

\section{Discussion}

Tooth eruption is a local event whereby specific genes in the DF, which surrounds the unerupted tooth, are either upregulated or downregulated at critical times to bring about the osteoclastogenesis and osteogenesis required for eruption (1). Previous studies have investigated the gene and protein
Table I. Experimental design of difference gel electrophoresis gels.

\begin{tabular}{|c|c|c|c|}
\hline \multirow[b]{2}{*}{ Gel no. } & \multicolumn{3}{|c|}{ Fluorescent CyDye labeling } \\
\hline & (Cy2) & (Су3) & (Cy5) \\
\hline 1 & Internal standard & Control & CSF \\
\hline 2 & Internal standard & CSF & Control \\
\hline 3 & Internal standard & Control & IL-1 \\
\hline 4 & Internal standard & IL-1 & Control \\
\hline 5 & Internal standard & CSF & IL-1 \\
\hline 6 & Internal standard & IL-1 & CSF \\
\hline
\end{tabular}

CSF, colony stimulating factor-1; IL-1, interleukin-1.

Table II. Primer sequences used in RT-qPCR.

\begin{tabular}{llc}
\hline Gene & \multicolumn{1}{c}{ Primers } & $\begin{array}{c}\text { Length } \\
\text { (bp) }\end{array}$ \\
\hline \multirow{2}{*}{ Vimentin F: 5'-GCCCAGATTCAGGAACAGCA-3' } & 216 \\
& R: 5'-TTCGTTTGACTCCTGCTTTGC-3' & \\
\multirow{2}{*}{ Actin } & F: 5'-TGCTATGTTGCCCTAGACTTCG-3' & 240 \\
& R: 5'-GTTGGCATAGAGGTCTTTACGG-3' \\
\multirow{2}{*}{ HSP25 } & F: 5'-AAAATACCCGGCTGGACACC-3' & 242 \\
& R: 5'-CCACTCATCGGGAAACCGAG-3' & \\
Rab-3D & F: 5'-AGGACTGGGCTACGCAGATTA-3' & 97 \\
& R: 5'-GATACGACCCGTTCATCCTCC-3' & \\
GAPDH & F: 5'-CAGGGCTGCCTTCTCTTGT-3' & 76 \\
& R: 5'-TGATGGGTTTCCCATTGATGA-3' & \\
\hline
\end{tabular}

HSP25, heat shock protein $\beta$-1; GAPDH, glyceraldehyde 3-phosphate dehydrogenase; F, Forward; R, Reverse.

profiles of DFCs after osteogenic differentiation (12-14). Morsczeck et al (14) used 2-DE combined with capillary liquid chromatography-tandem mass spectrometry analysis to profile differentially regulated proteins upon DF precursor cell differentiation, identifying 115 differentially regulated proteins. Upregulated proteins were associated with actin bundling and defense against oxidative cellular stress, whereas downregulated proteins were associated with collagen biosynthesis (14). In the present study, the effects of CSF-1 and IL- $1 \alpha$ treatment on DFCs were investigated using differential proteomics techniques, and the characteristic molecular markers for tooth eruption were analyzed. Proteins that were found to be upregulated as a result of treatment were cytoskeletal proteins and those involved in stress and secretion. Downregulated proteins were associated with protein degradation, metal-binding and the cell cycle. The observed changes in the expression of these proteins indicate that CSF-1 and IL- $1 \alpha$ regulate both osteogenesis and bone resorption to promote alveolar bone remodeling during the process of tooth eruption.

The cytoskeleton is an intracellular matrix that supports cell shape and function. The cytoskeletal systems of different 

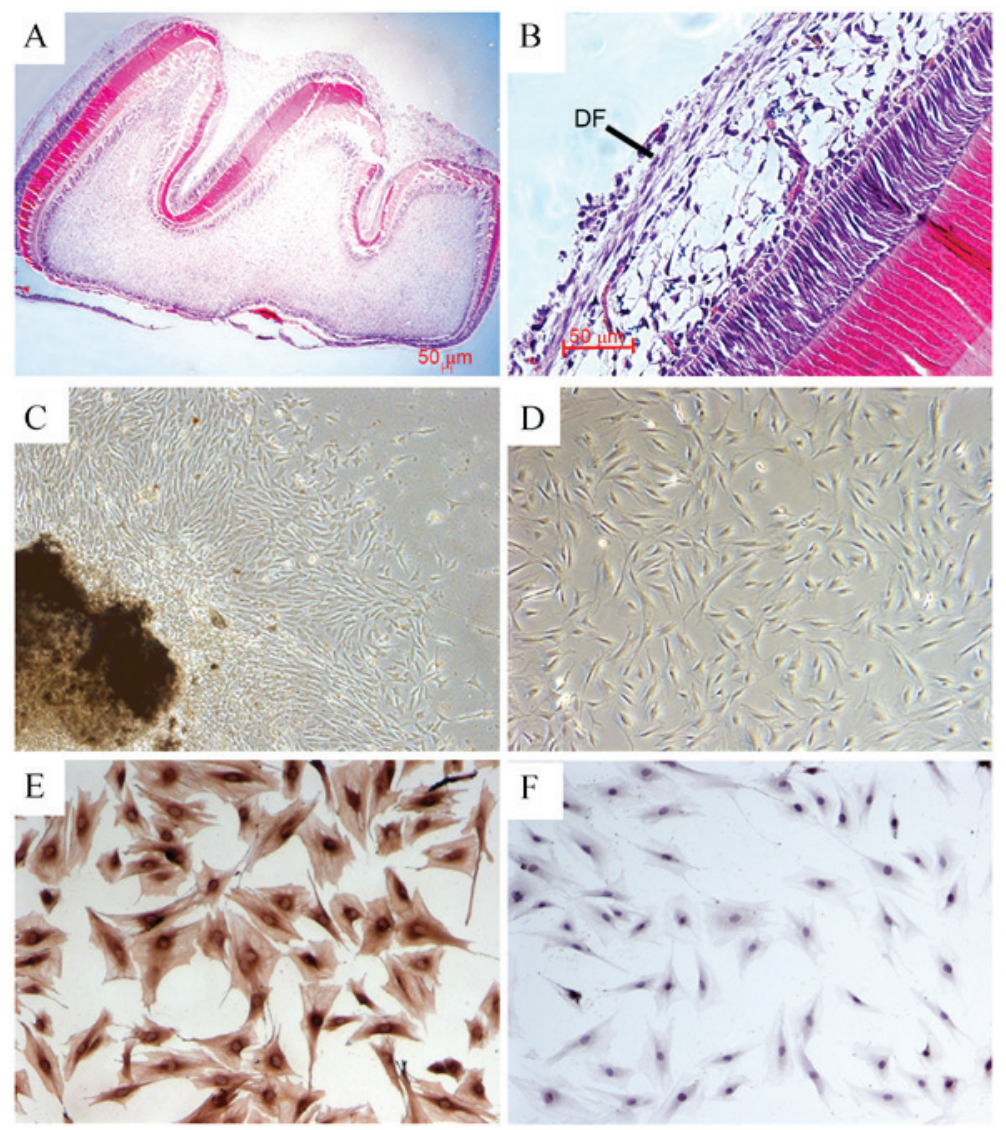

Figure 1. Morphological features of DFCs. (A and B) Hematoxylin and eosin staining of the rat first molar germs showed that the DF is present in the outer layer. (C) Primary DFCs surrounding the rat DF (magnification, x50). (D) DFCs following 3 passages (magnification, x100). (E) Vimentin staining of DFCs was positive (magnification, x200). (F) Keratin staining of DFCs was negative (magnification, x200). DFCs, dental follicle cells; DF, dental follicle.

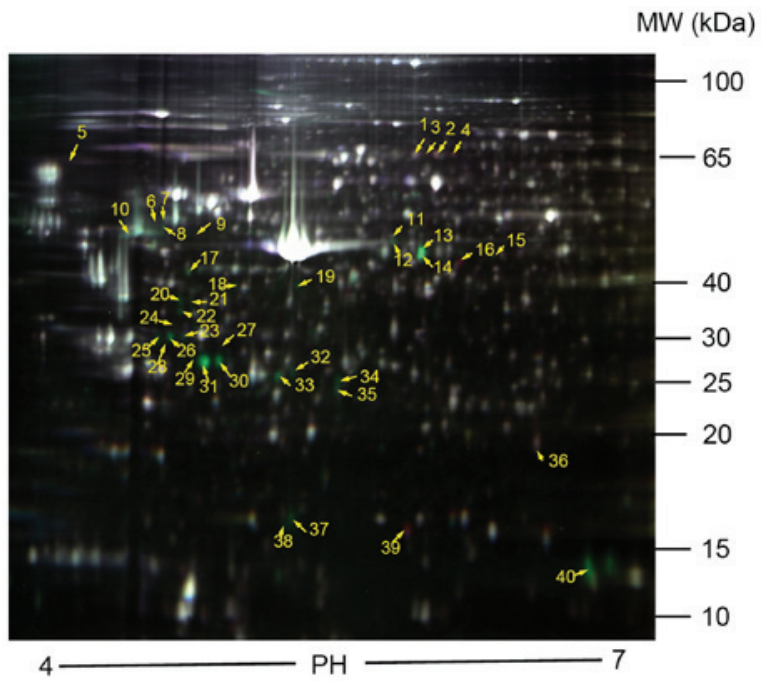

Figure 2. Proteomic profiling of DFCs treated with interleukin-1 $\alpha$ and colony stimulating factor-1 as revealed by two-dimensional-difference gel electrophoresis analysis. The $\mathrm{pH}$ range was 4.0-7.0 and the molecular mass separation was $10-100 \mathrm{kDa}$. Protein spots with abundance ratios $>1.5$ or $<-1.5$ were determined to be differentially expressed, and were subject to matrix-assisted laser desorption/ionization-time of flight-mass spectrometry and database searching. Arrows indicate the positions of 40 identified proteins and numbers correspond to the spot IDs listed in Table III.

organisms are composed of similar proteins. However, the structure, function and dynamic behavior of the cytoskeleton can vary, depending on the organism and cell type (18). Vimentin is a cytoskeletal intermediate filament protein found in cells of mesenchymal origin including fibroblasts, endothelial cells and leukocytes. Vimentin, tubulin and microfilaments form the entire cytoskeletal network. Previous studies have shown that vimentin is associated with apoptosis (19) and may function in immunity (20). Lian et al (21) reported that vimentin production is stimulated by $\mathrm{TGF} \beta$ via phosphoinositide 3-kinase/Akt/mechanistic target of rapamycin signaling, which leads to the suppression of activating transcription factor 4-dependent Ocn transcription and osteoblast differentiation. In human tooth germs, mesenchymal regions, such as the dental papilla and dental sac, predominantly express vimentin (22). In DFCs, vimentin is expressed and distributed in the intermediate filament (23), similar to the periodontal ligament cells (PDLCs) (24). Webb et al (25) investigated the expression of vimentin in rat DFCs and PDLCs at postnatal weeks 1, 2, 3, 4,8 and 12 by indirect immunofluorescence, and observed that the expression of vimentin in DFCs or PDLCs is always positive during tooth development. In the current study, IL-1 $\alpha$ was found to upregulate the expression of vimentin in rat DFCs. This suggests that vimentin may participate in the regulation of DFC differentiation and bone resorption during the process of tooth eruption. Further investigation will be required to elucidate the mechanisms by which vimentin regulates DFC differentiation.

Actin is expressed universally in eukaryotic cells and has been implicated in the division, migration, growth and 
Table III. Proteins with altered expression identified by 2D-DIGE/matrix assisted laser desorption/ionization-time of flight-mass spectrometry.

A, Proteins differentially expressed between IL-1-treated and control samples

\begin{tabular}{|c|c|c|c|c|c|c|c|c|}
\hline Pos. & Master no. & Av. ratio & $\begin{array}{c}\text { Protein name } \\
\text { (Rattus norvegicus) }\end{array}$ & $\begin{array}{c}\text { NCBI } \\
\text { accession no. }\end{array}$ & Score & $\begin{array}{l}\mathrm{MW} \\
(\mathrm{kDa})\end{array}$ & $\mathrm{pI}$ & P-value \\
\hline \multicolumn{9}{|c|}{ Cytoskeleton } \\
\hline 6 & 1460 & 1.75 & Vimentin & gil14389299 & 107 & 45 & 4.77 & $5.5 \times 10^{-3}$ \\
\hline 7 & 1471 & 2.27 & Vimentin & gil14389299 & 480 & 45 & 4.81 & $1.9 \times 10^{-5}$ \\
\hline 8 & 1516 & 1.54 & Vimentin & gil14389299 & 342 & 44 & 4.78 & $7.9 \times 10^{-4}$ \\
\hline 9 & 1529 & 1.87 & Vimentin & gil14389299 & 86 & 44 & 4.92 & $3.7 \times 10^{-3}$ \\
\hline 10 & 1530 & 1.93 & Vimentin & gil14389299 & 246 & 44 & 4.65 & $1.0 \times 10^{-4}$ \\
\hline 13 & 1635 & 11.71 & Actin, cytoplasmic 1 & gil13592133 & 552 & 44 & 5.96 & $3.8 \times 10^{-9}$ \\
\hline 14 & 1668 & 3.94 & Actin, cytoplasmic 1 & gil13592133 & 556 & 44 & 5.96 & $2.8 \times 10^{-9}$ \\
\hline 15 & 1680 & 2 & Actin, cytoplasmic 1 & gil13592133 & 138 & 44 & 6.28 & $3.8 \times 10^{-3}$ \\
\hline 17 & 1758 & 2.28 & Actin, cytoplasmic 1 & gil13592133 & 314 & 42 & 4.92 & $7.3 \times 10^{-7}$ \\
\hline 20 & 1925 & 5.29 & Actin, cytoplasmic 1 & gil13592133 & 131 & 38 & 4.89 & $4.4 \times 10^{-5}$ \\
\hline 21 & 1926 & 1.67 & Actin, cytoplasmic 2 & gil188536082 & 70 & 38 & 4.94 & $2.6 \times 10^{-3}$ \\
\hline 22 & 1991 & 3.15 & Actin, cytoplasmic 1 & gil13592133 & 174 & 36 & 4.89 & $2.1 \times 10^{-3}$ \\
\hline 23 & 2110 & 2.15 & $\begin{array}{l}\text { Actin, gamma-enteric } \\
\text { smooth muscle }\end{array}$ & gil25365 & 87 & 32 & 4.9 & $5.1 \times 10^{-4}$ \\
\hline 24 & 2114 & 7.53 & Actin, cytoplasmic 2 & gil188536082 & 179 & 32 & 4.84 & $1.2 \times 10^{-6}$ \\
\hline 27 & 2172 & 2.36 & Actin, cytoplasmic 1 & gil13592133 & 78 & 30 & 5.1 & $4.3 \times 10^{-6}$ \\
\hline 29 & 2214 & 5.45 & Actin, cytoplasmic 2 & gil188536082 & 53 & 28 & 4.95 & $3.8 \times 10^{-6}$ \\
\hline 30 & 2215 & 26.13 & Actin, cytoplasmic 1 & gil13592133 & 203 & 29 & 5.06 & $1.4 \times 10^{-7}$ \\
\hline 31 & 2221 & 26.06 & Actin, cytoplasmic 1 & gil13592133 & 226 & 28 & 4.99 & $2.6 \times 10^{-8}$ \\
\hline 33 & 2278 & 4.5 & Actin, cytoplasmic 1 & gil13592133 & 132 & 27 & 5.32 & $3.5 \times 10^{-6}$ \\
\hline 34 & 2292 & 3.23 & Actin, cytoplasmic 1 & gil13592133 & 85 & 26 & 5.59 & $1.7 \times 10^{-5}$ \\
\hline 37 & 2846 & 6.57 & Actin, cytoplasmic 1 & gil13592133 & 96 & 16 & 5.38 & $1.5 \times 10^{-6}$ \\
\hline 28 & 2203 & 1.59 & Lamin-A & gil383110 & 45 & 29 & 4.89 & $4.4 \times 10^{-4}$ \\
\hline 38 & 2875 & 3.95 & $\begin{array}{l}\text { Dystrophin-related } \\
\text { protein } 2\end{array}$ & gil13095924 & 46 & 16 & 5.35 & $4.0 \times 10^{-5}$ \\
\hline \multicolumn{9}{|c|}{ Stress } \\
\hline 11 & 1539 & 1.7 & $\begin{array}{l}78 \mathrm{kDa} \text { glucose- } \\
\text { regulated protein }\end{array}$ & gil25742763 & 61 & 44 & 5.83 & $3.0 \times 10^{-3}$ \\
\hline 12 & 1579 & 1.97 & $\begin{array}{l}78 \mathrm{kDa} \text { glucose- } \\
\text { regulated protein }\end{array}$ & gil25742763 & 115 & 44 & 5.84 & $3.9 \times 10^{-4}$ \\
\hline 35 & 2345 & 2.01 & $\begin{array}{l}\text { Heat shock protein } \\
\text { beta- } 1\end{array}$ & gil752993027 & 131 & 25 & 5.59 & $4.6 \times 10^{-5}$ \\
\hline \multicolumn{9}{|c|}{ Protein secretion and degradation } \\
\hline 18 & 1853 & 2.58 & $\begin{array}{l}\text { GTP-binding protein } \\
\text { Rab-3D }\end{array}$ & gil18034781 & 54 & 41 & 5.14 & $1.6 \times 10^{-5}$ \\
\hline 26 & 2169 & -1.8 & Cullin-5 & gil12083629 & 48 & 30 & 4.87 & $1.6 \times 10^{-3}$ \\
\hline \multicolumn{9}{|c|}{ Metal binding } \\
\hline 2 & 953 & -1.6 & $\begin{array}{l}\text { Serum albumin } \\
\text { precursor }\end{array}$ & gil158138568 & 180 & 66 & 6.03 & $1.1 \times 10^{-5}$ \\
\hline 4 & 963 & -1.91 & $\begin{array}{l}\text { Serum albumin } \\
\text { precursor }\end{array}$ & gil158138568 & 94 & 66 & 6.1 & $6.8 \times 10^{-6}$ \\
\hline 32 & 2252 & 2.27 & $\begin{array}{l}\text { 6-pyruvoyl } \\
\text { tetrahydrobiopterin } \\
\text { synthase }\end{array}$ & gil29498 & 18 & 27 & 5.38 & $2.1 \times 10^{-5}$ \\
\hline \multicolumn{9}{|c|}{ Cell cycle } \\
\hline 39 & 2883 & -3.09 & Cyclin-G1 & gil6978621 & 41 & 16 & 5.9 & $2.6 \times 10^{-6}$ \\
\hline \multicolumn{9}{|c|}{ Other } \\
\hline 5 & 1007 & -1.53 & DNA primase & gil6679461 & 51 & 65 & 4.4 & $4.0 \times 10^{-3}$ \\
\hline
\end{tabular}


Table III. Continued.

A, Proteins differentially expressed between IL-1-treated and control samples

\begin{tabular}{|c|c|c|c|c|c|c|c|c|}
\hline Pos. & Master no. & Av. ratio & $\begin{array}{c}\text { Protein name } \\
\text { (Rattus norvegicus) }\end{array}$ & $\begin{array}{c}\text { NCBI } \\
\text { accession no. }\end{array}$ & Score & $\begin{array}{l}\mathrm{MW} \\
(\mathrm{kDa})\end{array}$ & $\mathrm{pI}$ & P-value \\
\hline & & & large subunit & & & & & \\
\hline 16 & 1722 & -1.78 & $\begin{array}{l}\text { PDZ domain-containing } \\
\text { protein GIPC1 }\end{array}$ & gil16758060 & 268 & 43 & 6.11 & $1.1 \times 10^{-3}$ \\
\hline 25 & 2129 & 2.81 & $\begin{array}{l}\text { Transmembrane } \\
\text { protein } 43\end{array}$ & gil56090383 & 48 & 32 & 4.81 & $8.8 \times 10^{-6}$ \\
\hline 40 & 3034 & 1.78 & Disks large homolog 3 & gil13928878 & 34 & 14 & 6.73 & $2.5 \times 10^{-3}$ \\
\hline
\end{tabular}

B, Proteins differentially expressed between CSF-1-treated and control samples

\begin{tabular}{|c|c|c|c|c|c|c|c|c|}
\hline Pos. & Master no. & Av. ratio & Protein name ${ }^{\mathrm{a}}$ & $\begin{array}{c}\text { NCBI } \\
\text { accession no. }\end{array}$ & Score & $\begin{array}{l}\mathrm{MW} \\
(\mathrm{kDa})\end{array}$ & $\mathrm{pI}$ & P-value \\
\hline \multicolumn{9}{|c|}{ Cytoskeleton } \\
\hline 30 & 2215 & 1.63 & Actin, cytoplasmic 1 & gil13592133 & 203 & 29 & 5.06 & $1.4 \times 10^{-7}$ \\
\hline 31 & 2221 & 1.56 & Actin, cytoplasmic 1 & gil13592133 & 226 & 28 & 4.99 & $2.6 \times 10^{-8}$ \\
\hline \multicolumn{9}{|c|}{ Protein secretion and degradation } \\
\hline 36 & 2714 & 4.81 & $\begin{array}{l}\text { GTP-binding protein } \\
\text { Rab-3D }\end{array}$ & gil18034781 & 52 & 18 & 6.6 & $1.6 \times 10^{-5}$ \\
\hline 26 & 2169 & -1.56 & Cullin-5 & gil12083629 & 48 & 30 & 4.87 & $1.6 \times 10^{-3}$ \\
\hline \multicolumn{9}{|c|}{ Metal binding } \\
\hline 1 & 952 & -1.52 & Serum albumin & gil158138568 & 95 & 66 & 5.93 & $2.6 \times 10^{-4}$ \\
\hline 2 & 953 & -2.59 & Serum albumin & gil158138568 & 180 & 66 & 6.03 & $1.1 \times 10^{-5}$ \\
\hline 3 & 957 & -1.53 & Serum albumin & gil158138568 & 61 & 66 & 5.98 & $3.5 \times 10^{-3}$ \\
\hline 4 & 963 & -2.26 & Serum albumin & gil158138568 & 94 & 66 & 6.1 & $6.8 \times 10^{-6}$ \\
\hline \multicolumn{9}{|c|}{ Cell cycle } \\
\hline 39 & 2883 & -2.17 & Cyclin-G1 & gil6978621 & 41 & 16 & 5.9 & $2.6 \times 10^{-6}$ \\
\hline \multicolumn{9}{|c|}{ Other } \\
\hline 16 & 1722 & -1.63 & $\begin{array}{l}\text { PDZ domain- } \\
\text { containing protein }\end{array}$ & gil16758060 & 268 & 43 & 6.11 & $2.5 \times 10^{-3}$ \\
\hline
\end{tabular}

Pos., position of protein spots in the differential image gel; master no., number of protein spots in the 2D-DIGE gel; av. ratio, expression ratio of protein spots between control and treated samples; score, mass spectrum identification scores; MW, theoretical molecular weight; pI, isoelectric point; P-value, fold change calculated using ImageMaster 2D software; 2D-DIGE, two-dimensional-difference gel electrophoresis analysis.

structural stability of cells. There are three actin protein subtypes: $\alpha$-, $\beta$ - and $\gamma$-actin. Hosoya et al (26) reported the expression of $\alpha$-smooth muscle actin ( $\alpha$-SMA) in the DF in rat tooth development, and its distribution in the side of the alveolar bone indicated that $\alpha$-SMA may be a marker of the osteogenic differentiation in DFCs. San Miguel et al (27) reported $\alpha$-SMA-GFP expression during the early stages of primary cultures derived from the DF and periodontal ligaments. Expression was reduced in areas undergoing mineralization, suggesting that the $\alpha$-SMA promoter may be used to identify a population of osteoprogenitor cells residing within the DF and periodontal ligament that are able to differentiate into mature osteoblasts. The elevated expression levels of actin by CSF-1 and IL-1 $\alpha$ observed in the present study, indicates that CSF-1 and IL-1 $\alpha$ may stimulate the osteogenic differentiation of DFCs.

HSPs are one of the most widely conserved stress proteins that are produced by organisms in response to abnormal conditions. HSP25 (also known as HSP27/HSP $\beta 1$ ) is a member of the small HSP subfamily and protects cells from injury caused by stress factors and is involved in cell proliferation, differentiation and apoptosis. HSP25 serves an important role in tooth development, with persistent expression in enamel and dentin, and temporal expression in the pulp (28). A previous study demonstrated that HSP25 is localized exclusively in the odontoblast layer (29), suggesting that it is a marker of odontoblast differentiation $(30,31)$. Du et al (32) reported HSP25 immunoreactivity is increased chronologically during DF 
A
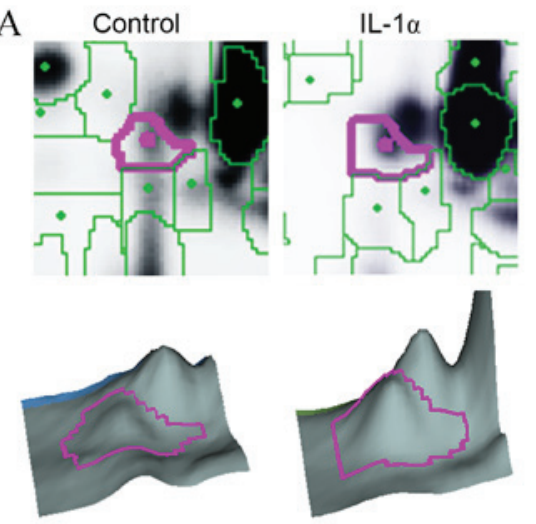

1530 Vimentin

C
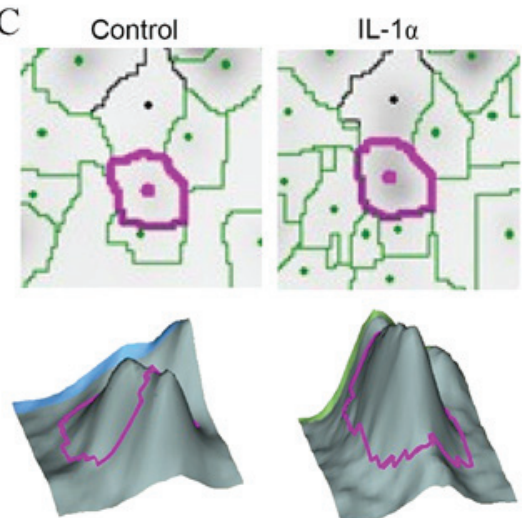

2345 Heat shock protein $\beta-1$
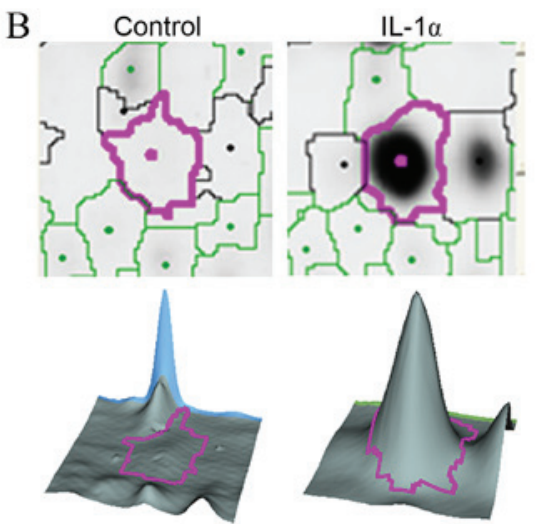

2221 Actin

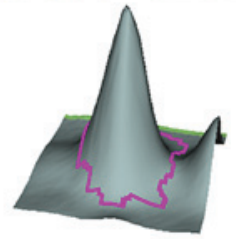

Cytoplasmic 1

D

Control

CSF-1
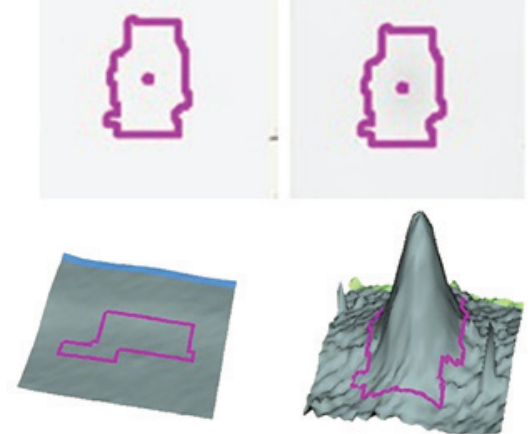

2714 GTP-binding protein Rab-3D

Figure 3. Comparative analysis of 4 protein spot intensities using the BVA module of the DeCyder software. Partial views of 2D (top panels) and 3D (bottom panels) gel images showing 4 selected protein spots within control and treated dental follicle cells. Spot boundaries of the selected proteins are displayed in pink. (A) Vimentin, (B) actin and cytoplasmic 1, (C) heat shock protein $\beta-1$ and (D) Rab-3D are upregulated in IL-1 $\alpha$ and CSF-1-treated cultures compared with the controls. IL, interleukin; CSF-1, colony stimulating factor-1.

A

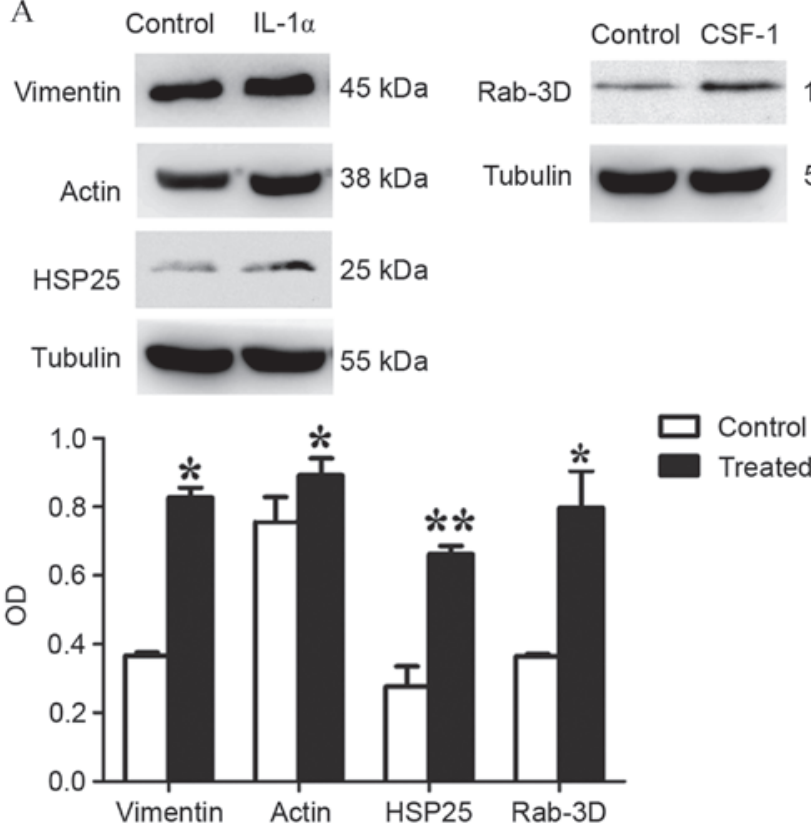

B

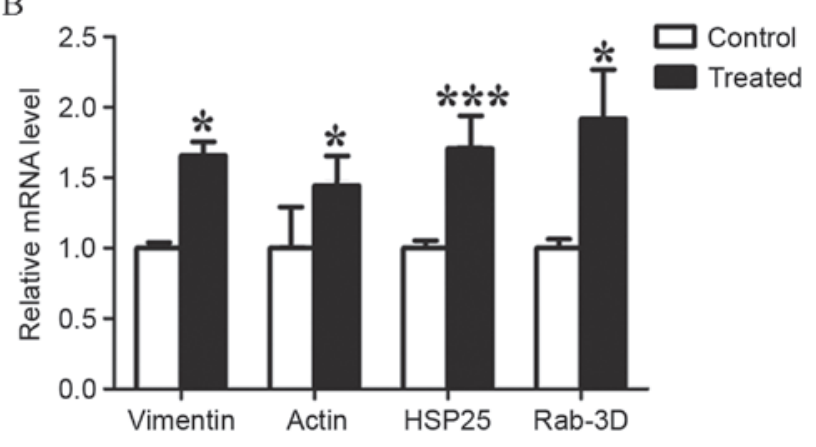

Figure 4. Western blotting and reverse transcription-quantitative polymerase chain reaction analysis of vimentin, actin, HSP25 and Rab-3D expression, in IL-1 $\alpha$ and CSF-1-treated DFCs. (A) Western blot analysis demonstrates that the protein expression of vimentin, actin, HSP25 and Rab-3D were significantly upregulated in treated DFC cultures compared with control cultures. (B) mRNA levels of vimentin, actin, HSP25 and Rab-3D were significantly upregulated in treated DFC cultures compared with control cultures. Values are presented as the mean \pm standard deviation and were calculated from 3 independent cell samples, with each cell sample repeated in triplicate. ${ }^{*} \mathrm{P}<0.05,{ }^{* * *} \mathrm{P}<0.05$ and ${ }^{* * * *} \mathrm{P}<0.001$ vs. control. HSP 25 , heat shock protein; IL, interleukin; CSF-1, colony stimulating factor-1; DFCs, dental follicle cells; OD, optical density. 
development. The protein was observed to have no significant effect on cell proliferation, however, it may play a role in cementoblast/osteoblast differentiation of DFCs. In the current study, HSP25 expression was observed to be significantly upregulated in the IL- $1 \alpha$-treated DFC group. This result may be due to the protective reaction to IL-1 $\alpha$ stimulation, which may bring about the cementoblast/osteoblast differentiation of DFCs.

Rab-3D is a member of the Rab3 subfamily (Rab3A/B/C/D) of small exocytotic GTPases, and represents a core component of the osteoclastic vesicle transport machinery (33). Rab-3D is expressed in non-neuronal cell types with high secretory requirements, where it localizes to specialized secretory vesicles (34-36). Pavlos et al (37) reported an osteosclerotic phenotype in Rab-3D-deficient mice. Further investigation revealed that Rab-3D modulates a post-trans-golgi network trafficking step that is required for osteoclastic bone resorption. In the present study, differential proteomics was conducted, which indicated that DFCs demonstrated increased expression of Rab-3D when induced by CSF-1. This was verified by western blotting and RT-qPCR analysis. These findings indicate that the activity of osteoclasts is regulated by the expression of Rab-3D in tooth eruption.

Furthermore, in the present study, cullin-5 and cyclin-G1 were downregulated in both the IL- $1 \alpha$ - and CSF-1-treated groups. Cullin-5 is a member of the cullin-RING E3 ubiquitin family, which is involved in a variety of biological processes, including the cell cycle and proliferation (38). The knockdown of cullin- 5 has been reported to promote cell growth by accelerating cell cycle progression in vitro (38). Cyclin-G1 is a member of the cyclin family of proteins, which control the progression of cells through the cell cycle by activating cyclin-dependent kinase (cdk) enzymes. Cyclin D1 has been suggested to be required for growth arrest prior to commitment to differentiation (39). Taking these observations into account, the results of the present study indicate that both IL- $1 \alpha$ and CSF-1 accelerate the cell cycle and the proliferation of DFCs. These results indicate a coregulation of cullin- 5 and cyclin-G1. Therefore, some form of interaction may occur between these two proteins, however, this interaction requires confirmation in future studies.

In conclusion, the present study identified the differential protein expression of DFCs following incubation with CSF-1 and IL-1 $\alpha$. These results suggest that CSF-1 and IL- $1 \alpha$ stimulate osteoclastogenesis (required for bone resorption and the initiation of the eruption pathway), and the osteogenic differentiation of DFCs. This investigation may provide new insights into tooth eruption. The molecular mechanisms through which CSF-1 and IL-1 $\alpha$ promote tooth eruption via the DF requires further study in order to provide an experimental foundation for the early diagnosis and prevention of delayed tooth eruption and impaction, in addition to novel therapeutic targets.

\section{Acknowledgements}

The present study was supported by the National Natural Science Foundation of China (grant nos. 81170932 and 81300846) and the Science and Technology Research Fund of Guangdong Province in China (grant no. B2013153).

\section{References}

1. Wise GE: Cellular and molecular basis of tooth eruption. Orthod Craniofac Res 12: 67-73, 2009.

2. Ten Cate AR: The development of the periodontium-a largely ectomesenchymally derived unit. Periodontol 2000 13:9-19, 1997.

3. Lee HS, Lee J, Kim SO, Song JS, Lee JH, Lee SI, Jung HS and Choi BJ: Comparative gene-expression analysis of the dental follicle and periodontal ligament in humans. PLoS One 8: e84201, 2013.

4. Wise GE and Fan W: Changes in the tartrate-resistant acid phosphatase cell population in dental follicles and bony crypts of rat molars during tooth eruption. J Dent Res 68: 150-156, 1989.

5. Bradaschia-Correa V, Moreira MM and Arana-Chavez VE: Reduced RANKL expression impedes osteoclast activation and tooth eruption in alendronate-treated rats. Cell Tissue Res 353: 79-86, 2013.

6. Wise GE, Lin F and Zhao L: Transcription and translation of CSF-1 in the dental follicle. J Dent Res 74: 1551-1557, 1995.

7. Que BG and Wise GE: Colony-stimulating factor-1 and monocyte chemotactic protein-1 chemotaxis for monocytes in the rat dental follicle. Arch Oral Biol 42: 855-860, 1997

8. Wise GE, Frazier-Bowers S and D'Souza RN: Cellular, molecular, and genetic determinants of tooth eruption. Crit Rev Oral Biol Med 13: 323-334, 2002.

9. Neves JS, Salmon CR, Omar NF, Narvaes EA, Gomes JR and Novaes PD: Immunolocalization of CSF-1, RANKL and OPG in the enamel-related periodontium of the rat incisor and their implications for alveolar bone remodeling. Arch Oral Biol 54: 651-657, 2009.

10. Van Wesenbeeck L, Odgren PR, MacKay CA, D'Angelo M, Safadi FF, Popoff SN, Van Hul W and Marks SC Jr: The osteopetrotic mutation toothless (tl) is a loss-of-function frameshift mutation in the rat Csf1 gene: Evidence of a crucial role for CSF-1 in osteoclastogenesis and endochondral ossification. Proc Natl Acad Sci USA 99: 14303-14308, 2002.

11. Huang $\mathrm{H}$ and Wise GE: Delay of tooth eruption in null mice devoid of the type I IL-1R gene. Eur J Oral Sci 108: 297-302, 2000.

12. Vollkommer T, Gosau M, Felthaus O, Reichert TE, Morsczeck C and Götz W: Genome-wide gene expression profiles of dental follicle stem cells. Acta Odontol Scand 73: 93-100, 2015.

13. Morsczeck C, Schmalz G, Reichert TE, Völlner F, Saugspier M, Viale-Bouroncle S and Driemel O: Gene expression profiles of dental follicle cells before and after osteogenic differentiation in vitro. Clin Oral Invest 13: 383-391, 2009.

14. Morsczeck C, Petersen J, Völlner F, Driemel O, Reichert T and Beck HC: Proteomic analysis of osteogenic differentiation of dental follicle precursor cells. Electrophoresis 30: 1175-1184, 2009.

15. Du Y, Ling J, Wei X, Ning Y, Xie N, Gu H and Yang F: Wnt/ $\beta$-catenin signaling participates in cementoblast/osteoblast differentiation of dental follicle cells. Connect Tissue Res 53: 390-397, 2012.

16. Wei X, Wu L, Ling J, Liu L, Liu S, Liu W, Li M and Xiao Y: Differentially expressed protein profile of human dental pulp cells in the early process of odontoblast-like differentiation in vitro. J Endod 34: 1077-1084, 2008.

17. Livak KJ and Schmittgen TD: Analysis of relative gene expression data using real-time quantitative PCR and the 2[-Delta Delta C(T)] method. Methods 25: 402-408, 2001.

18. Wickstead B and Gull K: The evolution of the cytoskeleton. J Cell Biol 194: 513-525, 2011.

19. van Engeland M, Kuijpers HJ, Ramaekers FC, Reutelingsperger CP and Schutte B: Plasma membrane alterations and cytoskeletal changes in apoptosis. Exp Cell Res 235: 421-430, 1997.

20. Mor-Vaknin N, Punturieri A, Sitwala K and Markovitz DM: Vimentin is secreted by activated macrophages. Nat Cell Biol 5: 59-63, 2003.

21. Lian N, Lin T, Liu W, Wang W, Li L, Sun S, Nyman JS and Yang X: Transforming growth factor $\beta$ suppresses osteoblast differentiation via the vimentin activating transcription factor 4 (ATF4) axis. J Biol Chem 287: 35975-35984, 2012.

22. Kero D, Kalibovic Govorko D, Vukojevic K, Cubela M, Soljic V and Saraga-Babic M: Expression of cytokeratin 8, vimentin, syndecan-1 and Ki-67 during human tooth development. J Mol Histol 45: 627-640, 2014.

23. Wise GE, Lin F and Fan W: Culture and characterization of dental follicle cells from rat molars. Cell Tissue Res 267: 483-492, 1992. 
24. Sculean A, Berakdar M, Windisch P, Remberger K, Donos N and Brecx M: Immunohistochemical investigation on the pattern of vimentin expression in regenerated and intact monkey and human periodontal ligament. Arch Oral Biol 48: 77-86, 2003.

25. Webb PP, Moxham BJ, Benjamin M and Ralphs JR: Changing expression of intermediate filaments in fibroblasts and cementoblasts of the developing periodontal ligament of the rat molar tooth. J Anat 188: 529-539, 1996.

26. Hosoya A, Nakamura H, Ninomiya T, Yoshiba K, Yoshiba N, Nakaya H, Wakitani S, Yamada H, Kasahara E and Ozawa H: Immunohistochemical localization of alpha-smooth muscle actin during rat molar tooth development. J Histochem Cytochem 54: 1371-1378, 2006

27. San Miguel SM, Fatahi MR, Li H, Igwe JC, Aguila HL and Kalajzic I: Defining a visual marker of osteoprogenitor cells within the periodontium. J Periodontal Res 45: 60-70, 2010.

28. Ohshima H, Ajima H, Kawano Y, Nozawa-Inoue K, Wakisaka S and Maeda T: Transient expression of heat shock protein (Hsp)25 in the dental pulp and enamel organ during odontogenesis in the rat incisor. Arch Histol Cytol 63: 381-395, 2000.

29. Nakasone N, Yoshie $\mathrm{H}$ and Ohshima H: An immunohistochemical study of the expression of heat-shock protein-25 and cell proliferation in the dental pulp and enamel organ during odontogenesis in rat molars. Arch Oral Biol 51: 378-386, 2006.

30. Masuda-Murakami Y, Kobayashi M, Wang X, Yamada Y, Kimura Y, Hossain M and Matsumoto K: Effects of mineral trioxide aggregate on the differentiation of rat dental pulp cells. Acta Histochem 112: 452-458, 2010.

31. Nakatomi M, Ida-Yonemochi $\mathrm{H}$ and Ohshima $\mathrm{H}$ : Lymphoid enhancer-binding factor 1 expression precedes dentin sialophosphoprotein expression during rat odontoblast differentiation and regeneration. J Endod 39: 612-618, 2013.
32. Du Y, Gu HJ, Gong QM, Yang F and Ling JQ: HSP25 affects the proliferation and differentiation of rat dental follicle cells. Int J Oral Sci 1: 72-80, 2009

33. Pavlos NJ, Cheng TS, Qin A, Ng PY, Feng HT, Ang ES, Carrello A, Sung CH, Jahn R, Zheng MH and Xu J: Tctex-1, a novel interaction partner of Rab3D, is required for osteoclastic bone resorption. Mol Cell Biol 31: 1551-1564, 2011.

34. Tian X, Jin RU, Bredemeyer AJ, Oates EJ, Błazewska KM, McKenna CE and Mills JC: RAB26 and RAB3D are direct transcriptional targets of MIST1 that regulate exocrine granule maturation. Mol Cell Biol 30: 1269-1284, 2010.

35. Evans E, Zhang W, Jerdeva G, Chen CY, Chen X, Hamm-Alvarez SF and Okamoto CT: Direct interaction between Rab3D and the polymeric immunoglobulin receptor and trafficking through regulated secretory vesicles in lacrimal gland acinar cells. Am J Physiol Cell Physiol 294: C662-C674, 2008.

36. Ngyen D, Jones A, Ojakian GK and Raffaniello RD: Rab3D redistribution and function in rat parotid acini. J Cell Physiol 197: 400-408, 2003

37. Pavlos NJ, Xu J, Riedel D, Yeoh JS, Teitelbaum SL, Papadimitriou JM, Jahn R, Ross FP and Zheng MH: Rab3D regulates a novel vesicular trafficking pathway that is required for osteoclastic bone resorption. Mol Cell Biol 25: 5253-5269, 2005.

38. Ma C, Qi Y, Shao L, Liu M, Li X and Tang H: Downregulation of miR-7 upregulates Cullin 5 (CUL5) to facilitate G1/S transition in human hepatocellular carcinoma cells. IUBMB Life 65: 1026-1034, 2013

39. Galderisi U, Jori FP and Giordano A: Cell cycle regulation and neural differentiation. Oncogene 22: 5208-5219, 2003. 